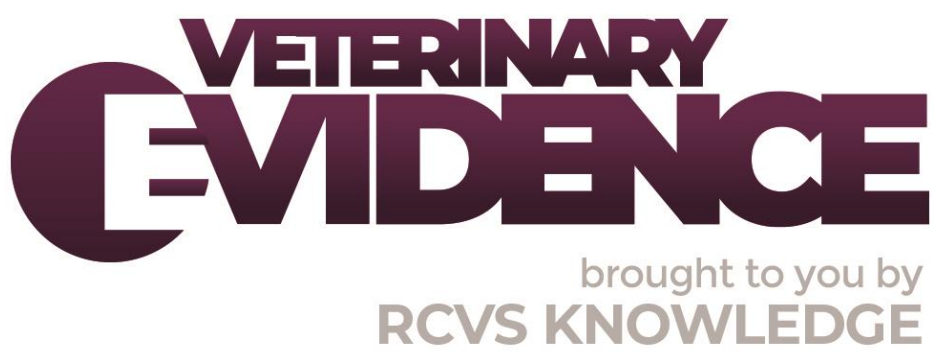

\title{
Thank You to Our Reviewers
}

Peter Cockcroft MA VetMB MSc DCHP DVM\&S DipECBHM MBA MRCVS ${ }^{1 *}$

\footnotetext{
${ }^{1}$ University of Surrey, School of Veterinary Medicine, Daphne Jackson Rd, Guildford GU2 7AL

*Corresponding Author (p.cockcroft@surrey.ac.uk)
}

ISSN: 2396-9776

Published: 07 Jan 2019

in: Vol 4, Issue 1

DOI: http://dx.doi.org/10.18849/ve.v4i1.236 
As Editor-in-chief I would like to thank all of our editors and reviewers for their continued support of the Veterinary Evidence journal and their diligence in meeting demanding timelines. Their knowledge, expertise and insights are duly acknowledged and highly valued. All reviewers who have taken the time to review for Veterinary Evidence are listed in the full text.

In the coming year we hope to develop a new approach and construct for the recognition and delivery of important information needs. This will take the form of a condition specific decision support algorithm with links to Knowledge Summaries providing the best current evidence. We also intend to publish a series of papers from targeted invited authors to highlight important areas of evidence-based practice including patient safety, quality improvement, business and workplace learning. We have also launched a Knowledge Summary competition for students studying veterinary medicine, veterinary nursing and veterinary bio-science, so that we may engage with the next generation of practice professionals.

I look forward to a challenging and innovative new year with your continued support.

Thank you to all who have contributed.

Nicola Ackerman

Jane Alexander

David Allman

Konstantinos Antonopoulos

Victoria Arbona

Sue Badger

David Barrett

Nicola Bates

Nick Bell

Jackie Belle

Hasan Bilgili

Tiffany Blackett

Bruce Bladon

Filip Blent

Tim Brazil 
Marnie Brennan

Katherine Briscoe

Andrew Brown

Marta Brscic

Christopher Bruce Riley

Louise Buckley

Sarah Caney

James Carmalt

Thomas Chambers

Marge Chandler

William Chandler

Scott Christopher

David Church

Jacqueline Cole

Polly Compston

Elena Contreras

Giulio Cozzi

Jonathan Cracknell

Linda Dahlgren

Julie De Lasalle

Laura Dixon

Dario d'Ovidio

Ken Drobatz

Anna Dunlap

Sushmitha Durgam

Sue Dyson 
Rebecca Elliott

Amanda-Jane Erne

Virginia Fajt

Erik Fausak

Mireia Fernandez

John Fishwick

Geoffry Fordyce

Myra Forster-van Hijfte

Mary Fraser

Lisa Freeman

Jennifer Garcia

Mark Garneau

Laura Garrett

Paula Giaretta

Toby Gimmel

Laurie Goodrich

Wanda Gordon-Evans

Cecilia Gorrel

Kelly Hall (Wilke)

Annick Hamaide

Anna Hammond

Jeanette Hanson

Frances Harcourt-Brown

Anke Hendricks

Katleen Hermans 
Jo Hockenhull

Mark Holmes

Shailen Jasani

Norman Johnston

Stephen Jones

Philip Kass

Nina Kieves

Stanley Kim

Simone Kirby

Matti Kiupel

Barbara Kohn

Sheila Laverty

Daniel Lewis

Matyas Liptovszky

Jason Lombard

Leo Londono

David Maggs

Denis Marcellin-Little

Stanley Marks

Cathy McGowan

Maureen McMichael

Anna Meredith

Gillian Monsell

Stewart Morgan

Andy Morris

Philippa Morrison 
Pam Mosedale

Morag Moseley

Hans Nauwynck

Stéphanie Noël

Ingo Nolte

Marianna Norring

Nicole Northrup

Kazuya Oikawa

Mateus Paranhos da Costa

Russell Parker

Andrew Parry

Bob Partridge

Rachel Perry

Federica Pirrone

Simon Platt

Siegfried Platz

Brian Pound

Antonio Pozzi

Nicola Robinson

Pete Rodgers

Jeffrey Runge

Silke Salavati

Richard Saunders

Michael Schaer

Silke Schmitz 
Stefan Schwarz

Phil Scott

Gonçalo Serrano

Bradley Simon

Lisa Smart

Bruce Smith

Eva Spada

Kit Sturgess

Meghan Sullivan

Jo Suthers

Sienna Taylor

David Thomas

Mickey Tivers

Mandy Wallace

Lisa Weeth

Becky Whay

Constance White

Richard White

Roger Wilkinson

John Williams

Cenk Yardimci 


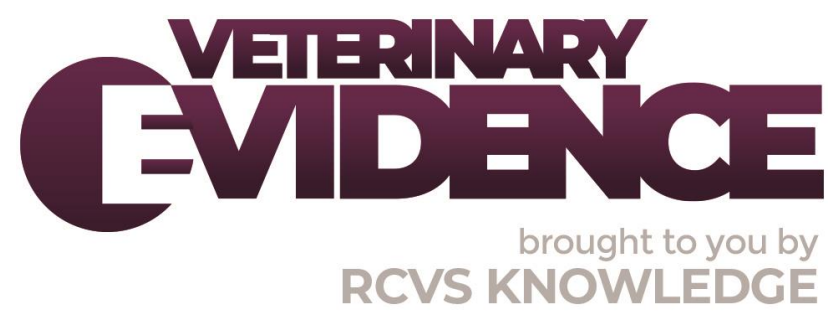

\section{Intellectual Property Rights}

Authors of Knowledge Summaries submitted to RCVS Knowledge for publication will retain copyright in their work, and will be required to grant RCVS Knowledge a non-exclusive license of the rights of copyright in the materials including but not limited to the right to publish, re-

publish, transmit, sell, distribute and otherwise use the materials in all languages and all media throughout the world, and to license or permit others to do so.

\section{Disclaimer}

Any opinions expressed in articles and other publication types published in Veterinary Evidence are the author's own and do not necessarily reflect the view of the RCVS Knowledge. Veterinary Evidence is a resource to help inform, and the content herein should not override the responsibility of the practitioner. Practitioners should also consider factors such as individual clinical expertise and judgement along with patient's circumstances and owners' values. Authors are responsible for the accuracy of the content. While the Editor and Publisher believe that all content herein are in accord with current recommendations and practice at the time of publication, they accept no legal responsibility for any errors or omissions, and make no warranty, express or implied, with respect to material contained within.

For further information please refer to our Terms of Use.

RCVS Knowledge is the independent charity associated with the Royal College of Veterinary Surgeons (RCVS). Our ambition is to become a global intermediary for evidence based veterinary knowledge by providing access to information that is of immediate value to practicing veterinary professionals and directly contributes to evidence based clinical decision-making.

\section{https://www.veterinaryevidence.org/}

RCVS Knowledge is a registered Charity No. 230886.

Registered as a Company limited by guarantee in England and Wales No. 598443.

Registered Office: Belgravia House, 62-64 Horseferry Road, London SW1P 2AF

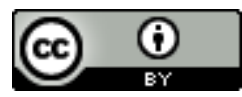

This work is licensed under a Creative Commons Attribution 4.0 International License. 